Supplement of Geosci. Model Dev., 11, 2563-2579, 2018

https://doi.org/10.5194/gmd-11-2563-2018-supplement

(C) Author(s) 2018. This work is distributed under

the Creative Commons Attribution 4.0 License.

(c) (1)

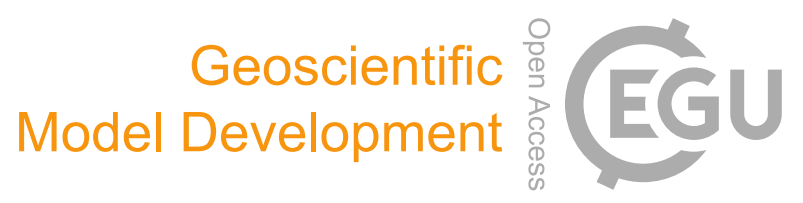

Supplement of

\title{
Comparison of spatial downscaling methods of general circulation model results to study climate variability during the Last Glacial Maximum
}

Guillaume Latombe et al.

Correspondence to: Guillaume Latombe (latombe.guillaume@gmail.com)

The copyright of individual parts of the supplement might differ from the CC BY 4.0 License. 
Table S1. Names and coordinates of the validation sites.

\begin{tabular}{|c|c|c|c|c|c|}
\hline \multicolumn{6}{|c|}{ LGM } \\
\hline \multicolumn{3}{|c|}{ BCI } & \multicolumn{3}{|c|}{ Pollen } \\
\hline Site & Latitude & Longitude & Site & Latitude & Longitude \\
\hline Gorham's cave & 36.12 & -5.34 & Padul & 37.00 & -3.67 \\
\hline Nerja & 36.76 & -3.85 & Monticchio Grande & 40.94 & 15.60 \\
\hline Ambrosio & 37.82 & -2.10 & Castiglione & 41.89 & 12.75 \\
\hline Escoural & 38.54 & -8.13 & Banyols & 42.13 & 2.75 \\
\hline Cendres & 38.69 & 0.15 & Ajo & 43.05 & -6.15 \\
\hline Portalon & 42.35 & -3.52 & Lourdes & 43.17 & -0.17 \\
\hline Abauntz & 43.00 & -1.63 & Biscaye & 43.27 & -2.70 \\
\hline Erralia & 43.18 & -2.22 & Bouchet & 44.89 & 3.67 \\
\hline Amalda & 43.21 & -2.18 & Les Echets & 45.67 & 4.89 \\
\hline Ekain & 43.24 & -2.28 & Grande Pile & 47.73 & 6.50 \\
\hline Miron & 43.25 & -3.45 & & & \\
\hline Hornos de la Pena & 43.26 & -4.03 & & & \\
\hline Urtiaga & 43.27 & -2.32 & & & \\
\hline Rascano & 43.28 & -3.70 & & & \\
\hline Beneito & 43.29 & -3.97 & & & \\
\hline Altamira & 43.38 & -4.12 & & & \\
\hline La Riera & 43.42 & -4.86 & & & \\
\hline Aitzbitarte & 43.43 & -3.67 & & & \\
\hline Ruso & 43.44 & -3.88 & & & \\
\hline
\end{tabular}



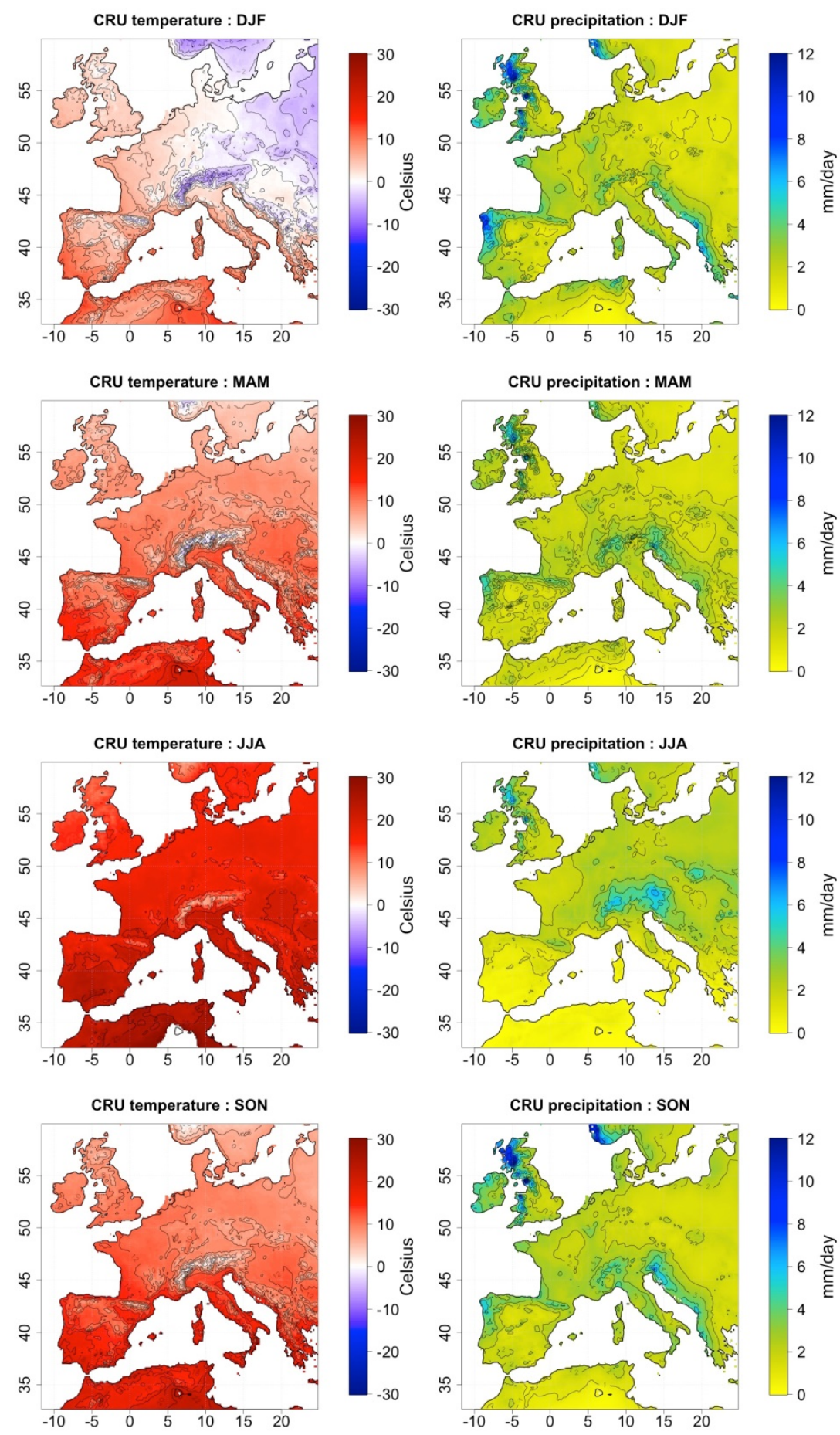

Figure S1. Fine-scale, present-day monthly temperature and daily precipitation dependent data from the Climate Research Unit (CRU), for winter (December, January, February), spring (March, April, May) summer (June, July, August) and autumn (September, October, November), computed from 1960 to 1990. 

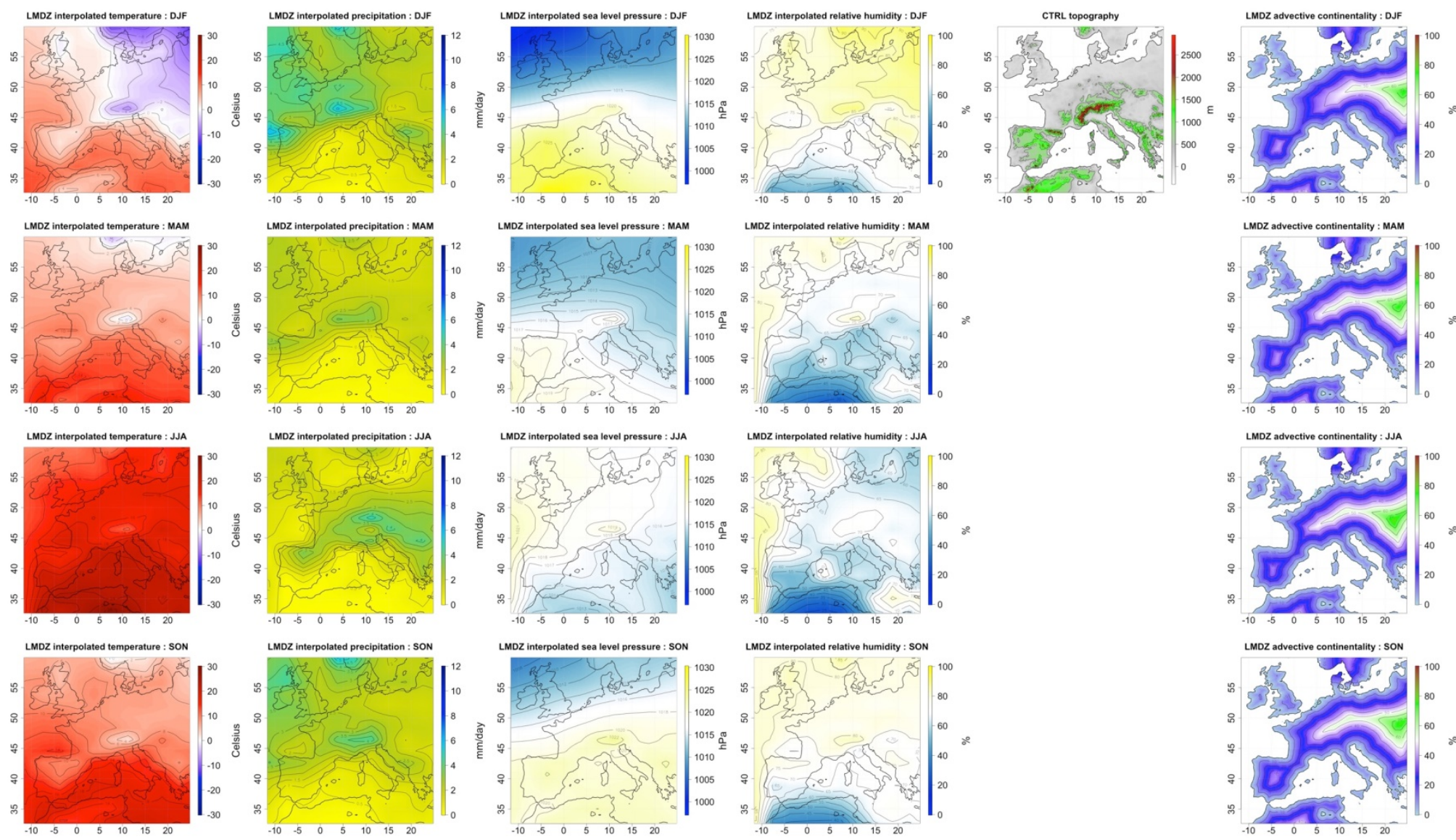

Figure S2. Mean distributions of the interpolated predictors (temperature, precipitation, sea level pressure, relative humidity, elevation and advective continentality) over Western Europe during the present-day period for winter (December, January, February), spring (March, April, May) summer (June, July, August) and autumn (September, October, November), computed over 31 years for the bilinear interpolation. 

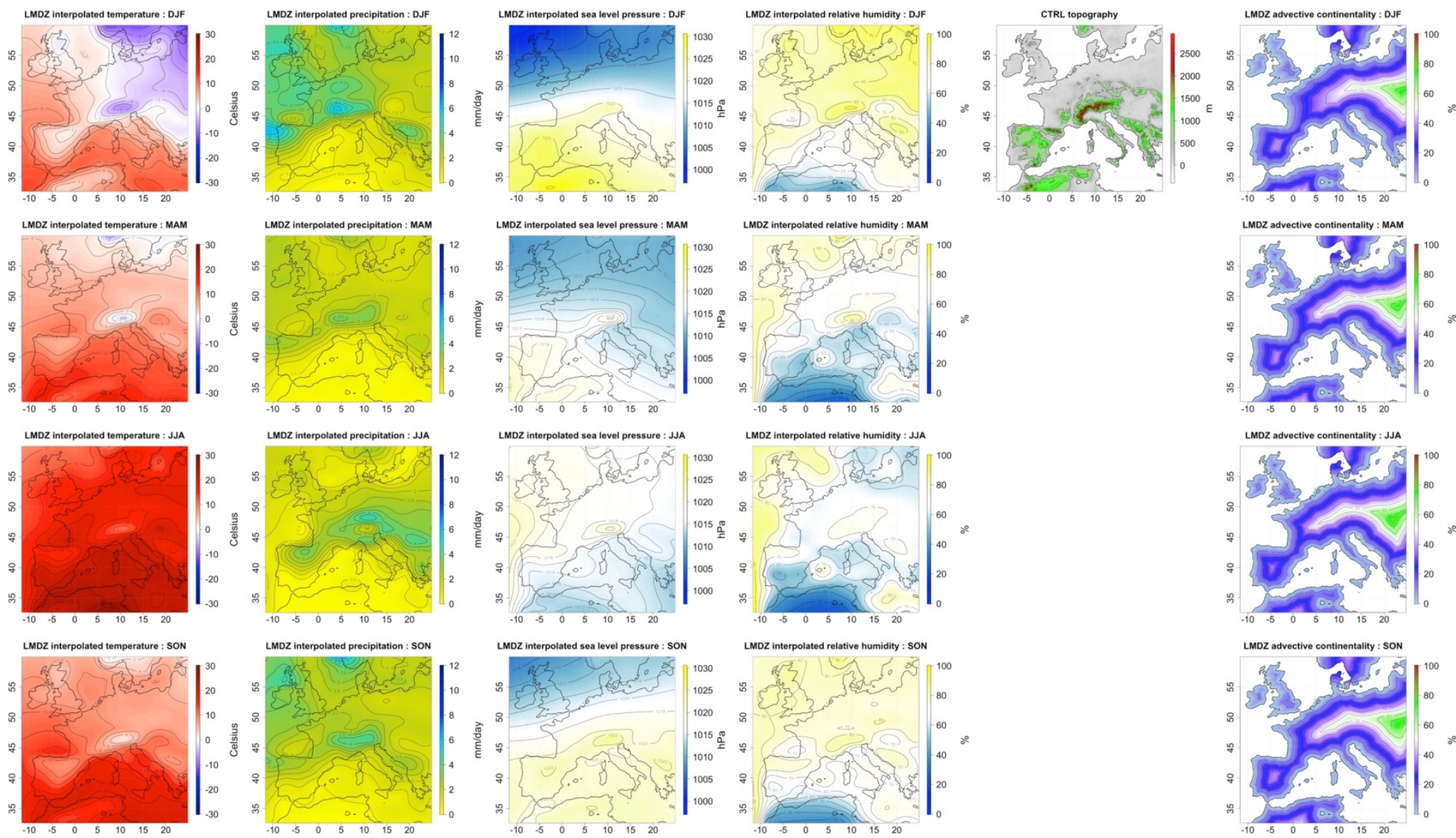

Figure S3. Mean distributions of the interpolated predictors (temperature, precipitation, sea level pressure, relative humidity, elevation and advective continentality) over Western Europe during the present-day period for winter (December, January, February), spring (March, April, May) summer (June, July, August) and autumn (September, October, November), computed over 31 years for the bicubic interpolation. 

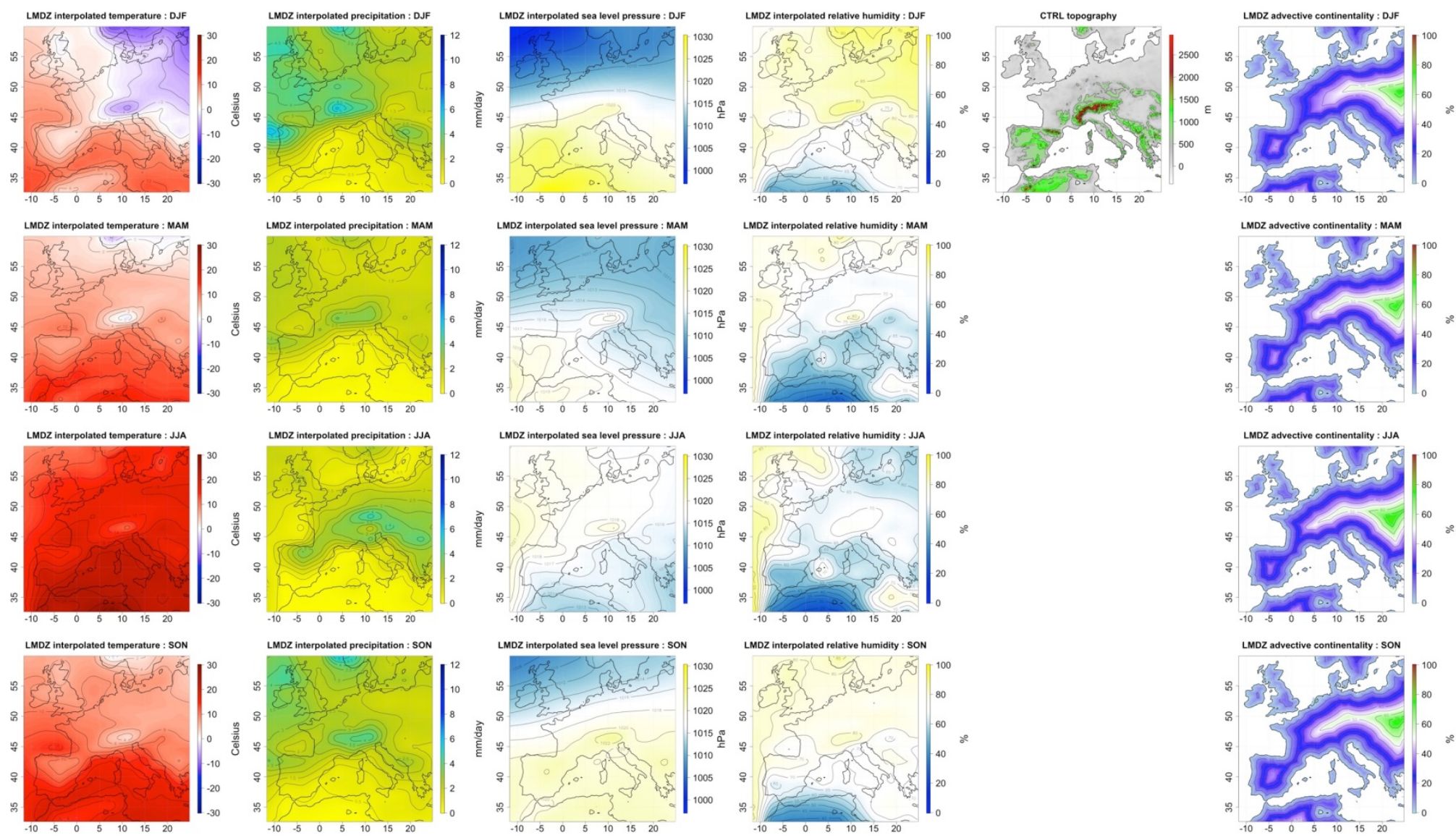

Figure S4. Mean distributions of the interpolated predictors (temperature, precipitation, sea level pressure, relative humidity, elevation and advective continentality) over Western Europe during the present-day period for winter (December, January, February), spring (March, April, May) summer (June, July, August) and autumn (September, October, November), computed over 31 years for the kriging. 

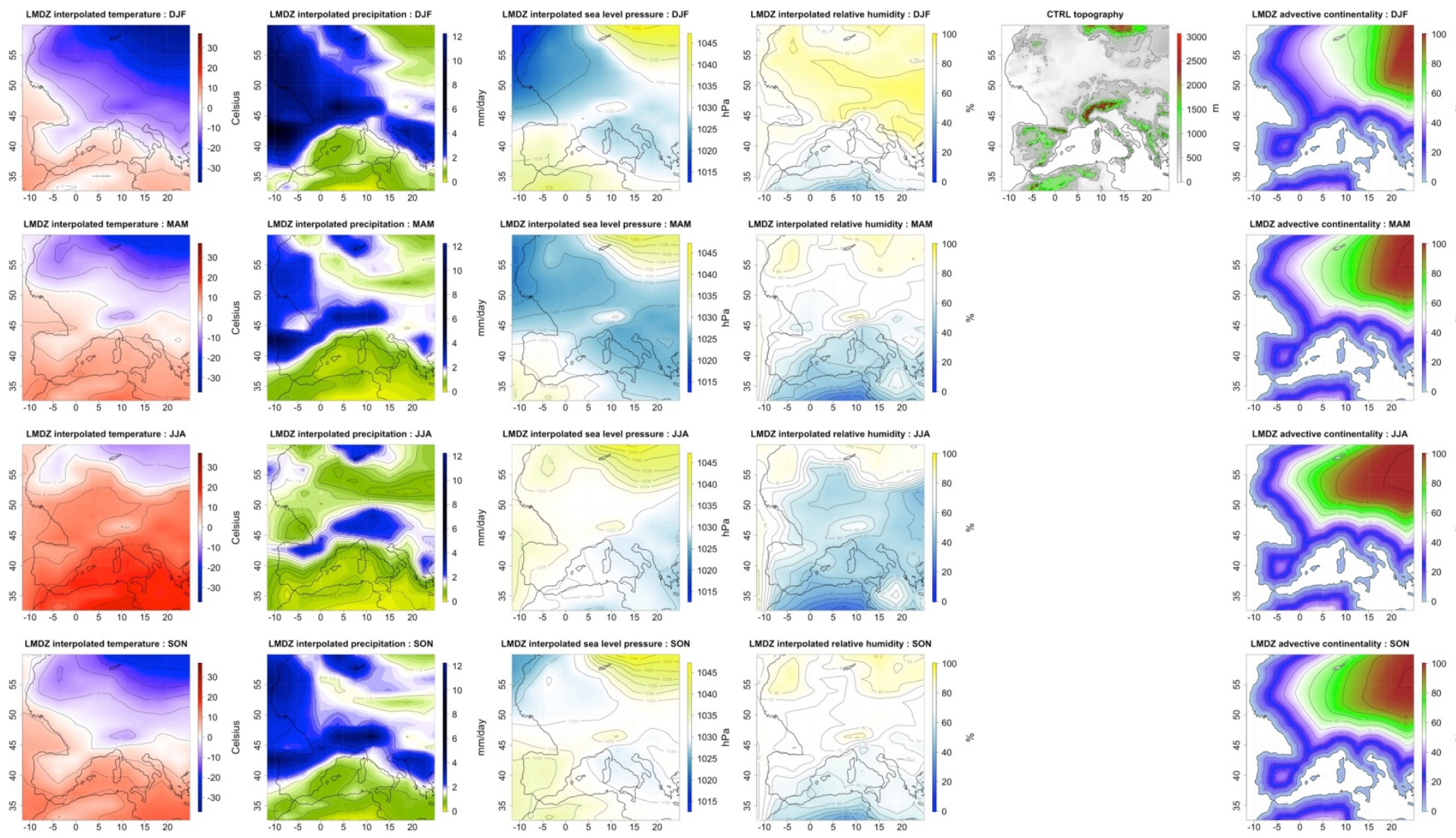

Figure S5. Mean distributions of the interpolated predictors (temperature, precipitation, sea level pressure, relative humidity, elevation and advective continentality) over Western Europe during the LGM for winter (December, January, February), spring (March, April, May) summer (June, July, August) and autumn (September, October, November), computed over 50 years for the bilinear interpolation. 

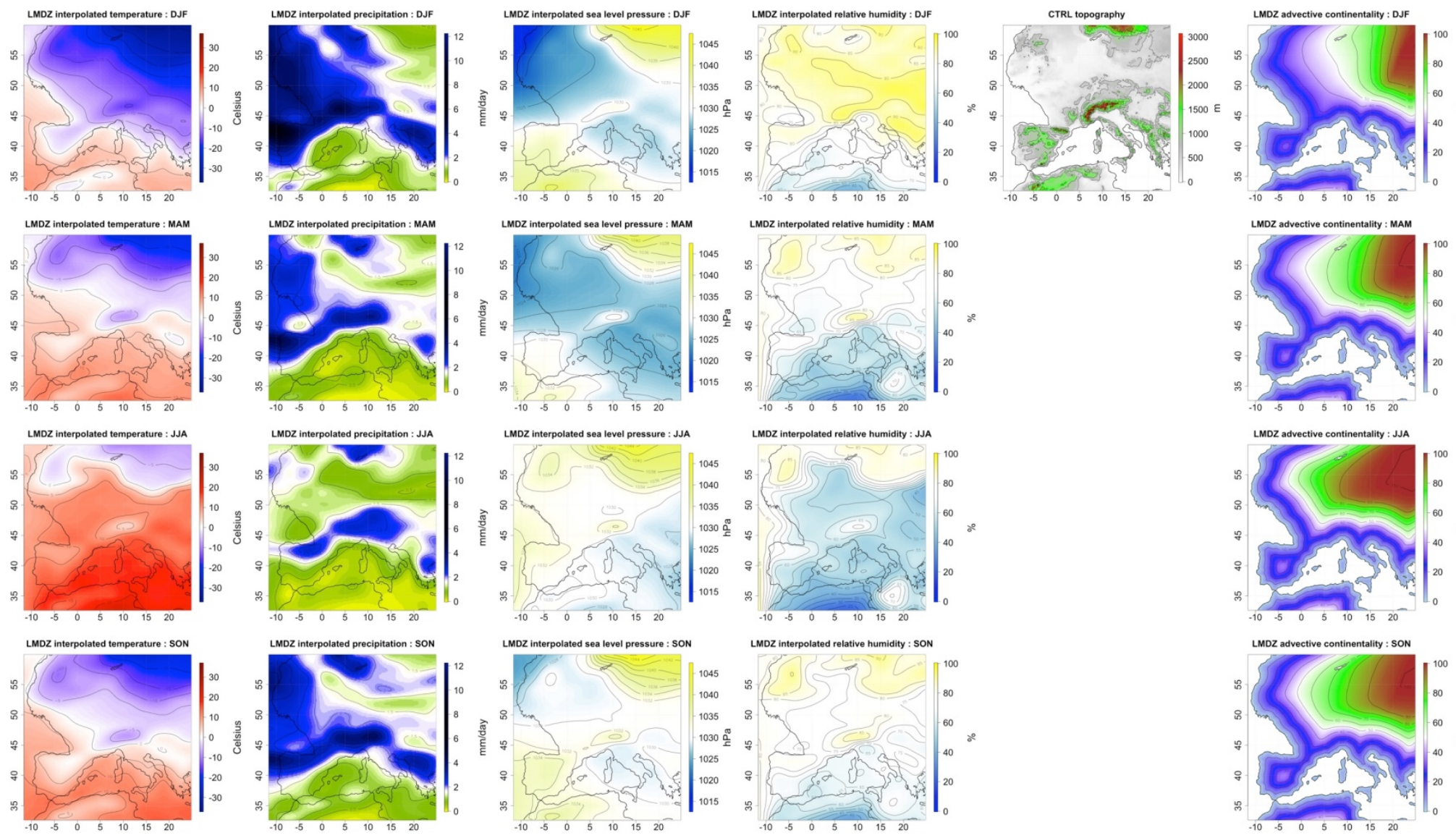

Figure S6 Mean distributions of the interpolated predictors (temperature, precipitation, sea level pressure, relative humidity, elevation and advective continentality) over Western Europe during the LGM for winter (December, January, February), spring (March, April, May) summer (June, July, August) and autumn (September, October, November), computed over 50 years for the bicubic interpolation. 

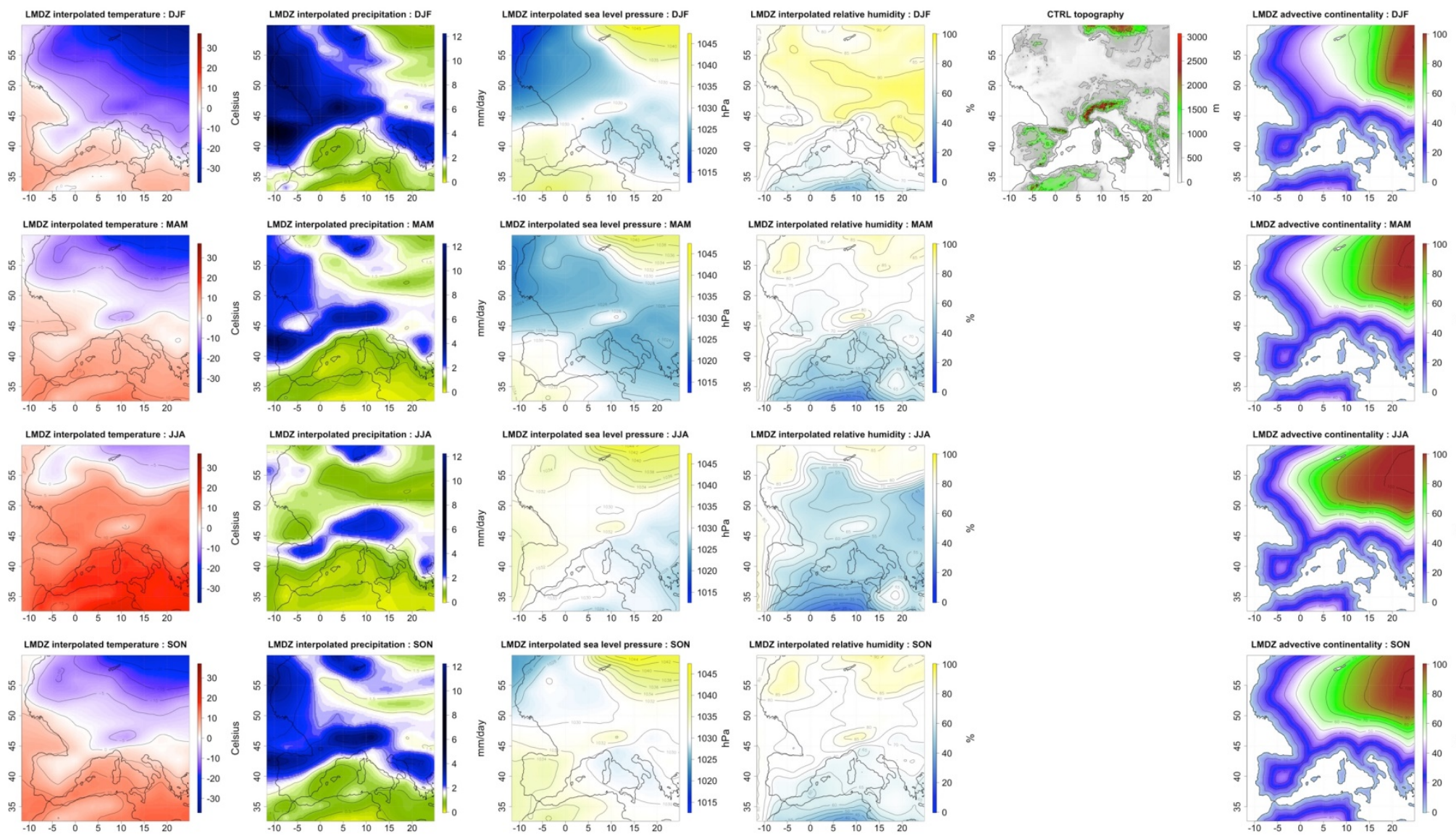

Figure S7. Mean distributions of the interpolated predictors (temperature, precipitation, sea level pressure, relative humidity, elevation and advective continentality) over Western Europe during the LGM for winter (December, January, February), spring (March, April, May) summer (June, July, August) and autumn (September, October, November), computed over 50 years for the kriging. 

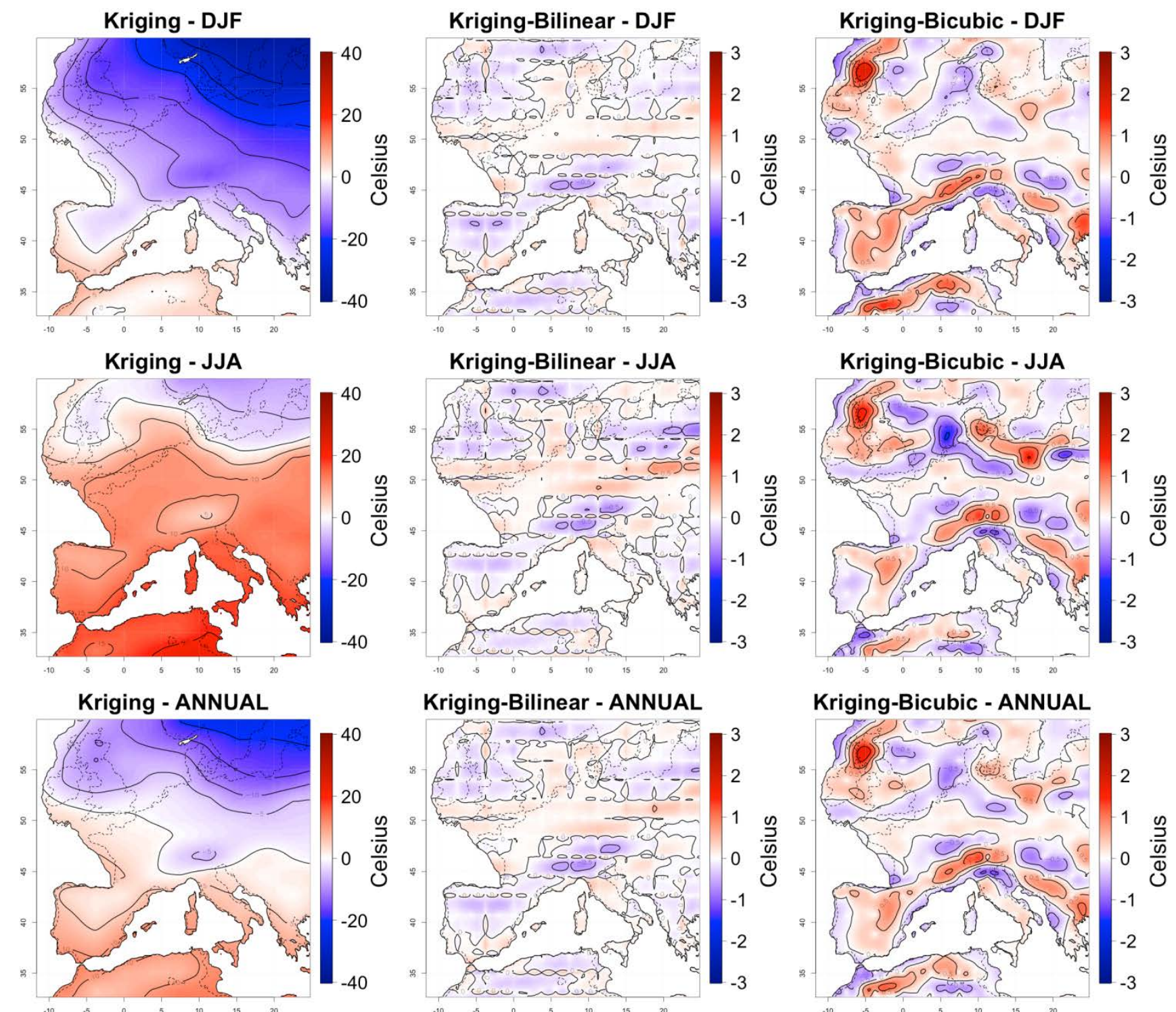

Figure S8. Mean distributions of interpolated monthly temperature over Western Europe during the LGM for winter (December, January, February), summer (June, July, August), and the whole year, computed over 50 years for the kriging interpolation techniques, and difference between the kriging and the other two techniques. Interpolations were performed for each month independently, but results are combined into seasons to summarise the 5 results. 

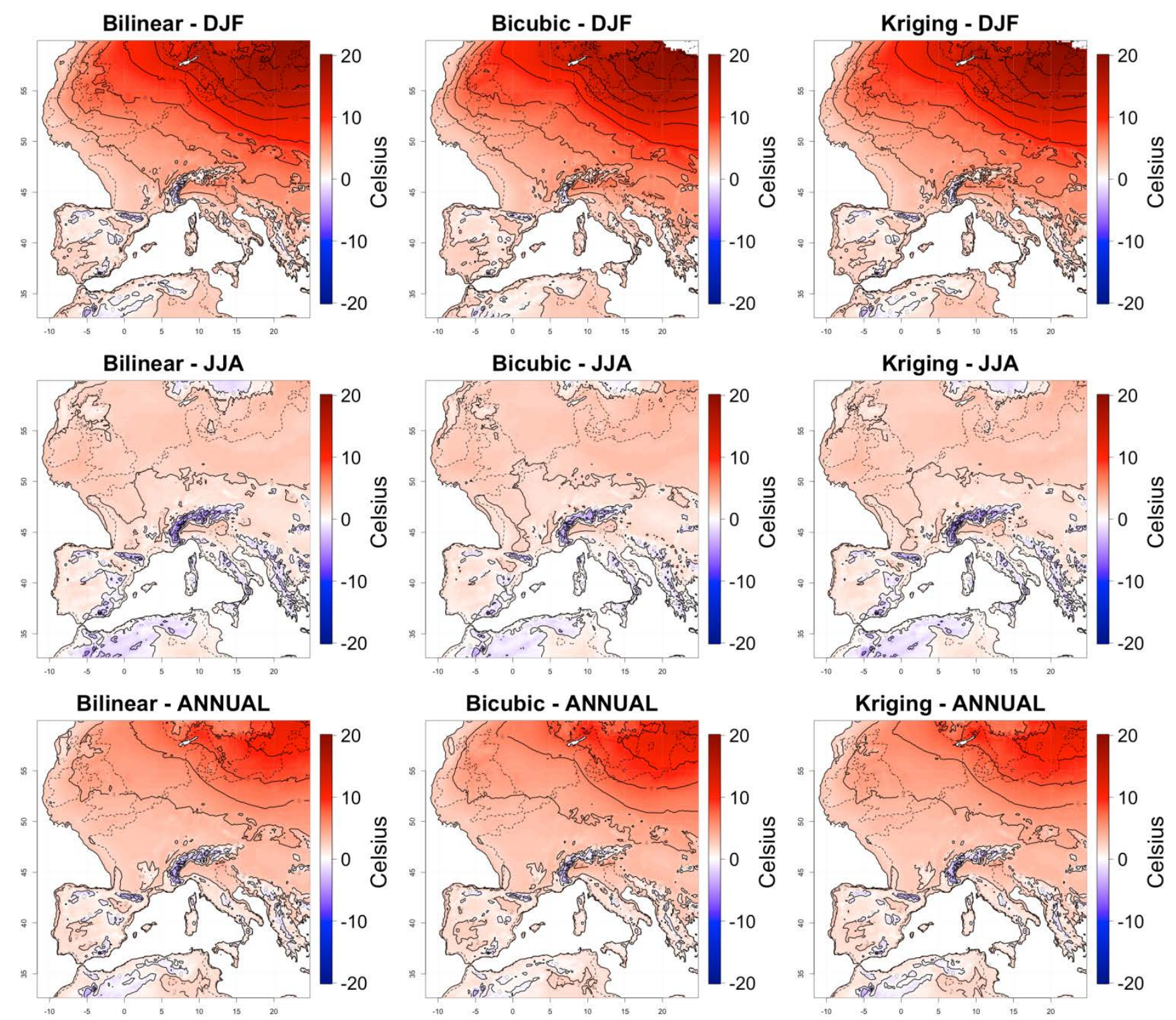

Figure S9. Difference in mean distributions of downscaled and interpolated monthly temperature over Western Europe during the LGM for winter (December, January, February), summer (June, July, August), and the whole year, computed over 50 years, for the three interpolation techniques. Downscaling and interpolations were performed for each month independently, but results are combined into seasons to summarise the results. 


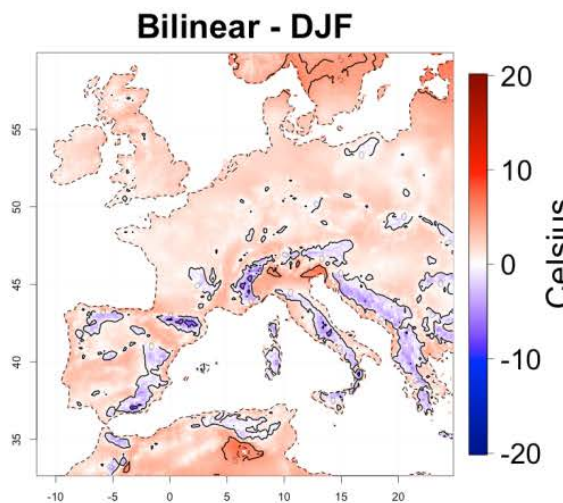

Bilinear - JJA
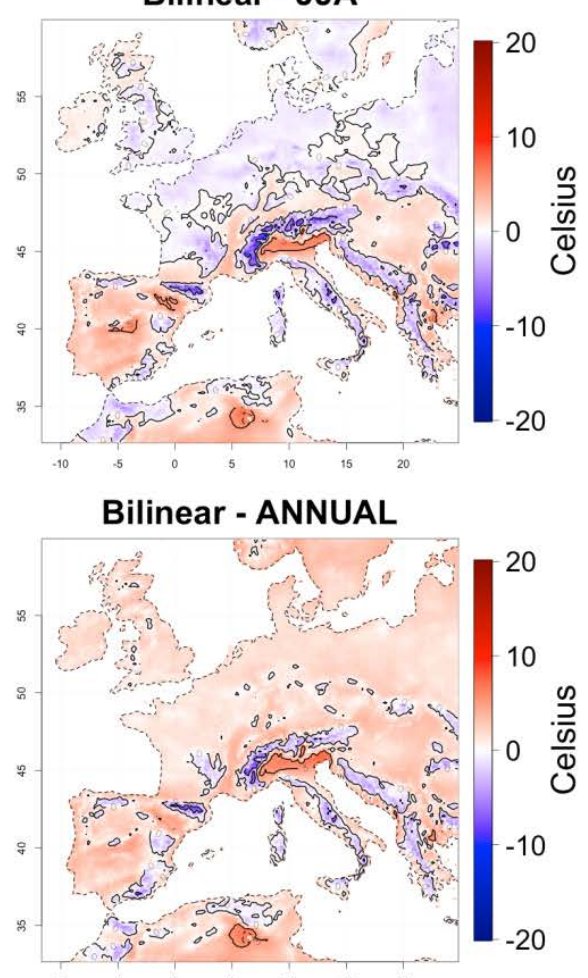

Bicubic - DJF

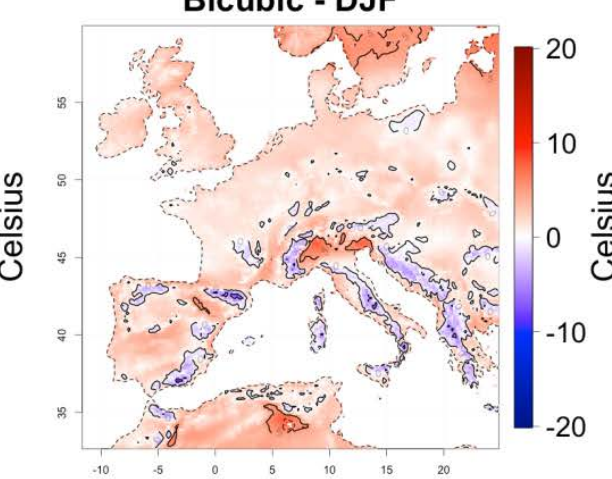

Bicubic - JJA
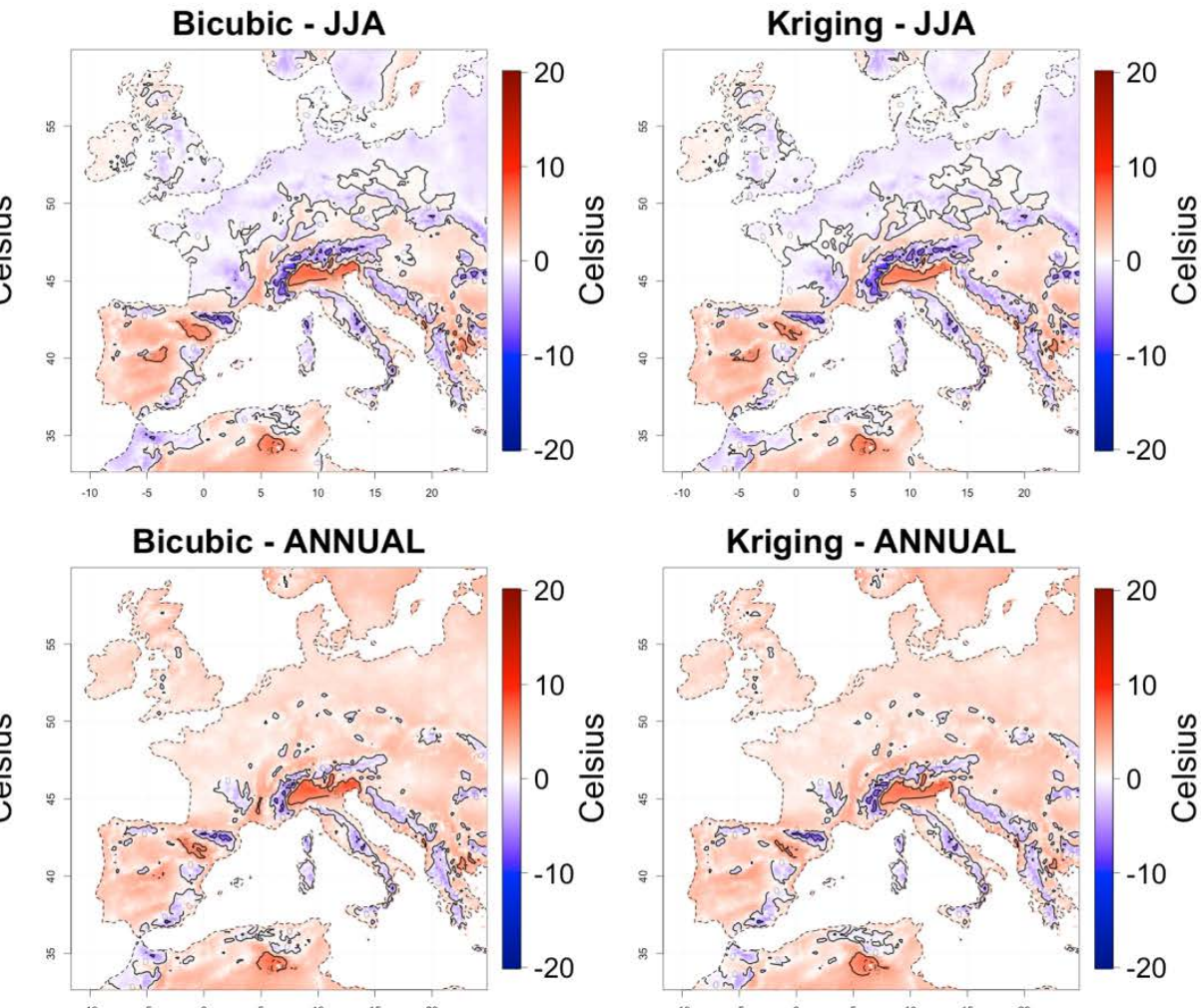

Kriging - DJF

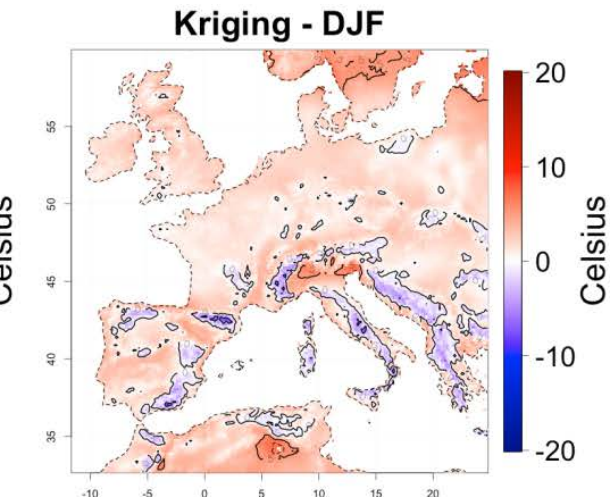

$\frac{\frac{N}{5}}{0}$

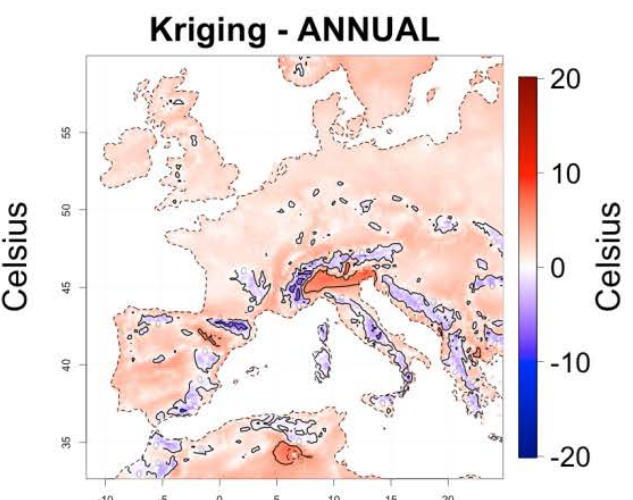

Figure S10. Difference in mean distributions of the CRU and interpolated monthly temperature over Western Europe for the present days for winter (December, January, February), summer (June, July, August), and the whole year for the three interpolation techniques. Interpolations were performed for each month independently, but results are combined into seasons to summarise the results. 

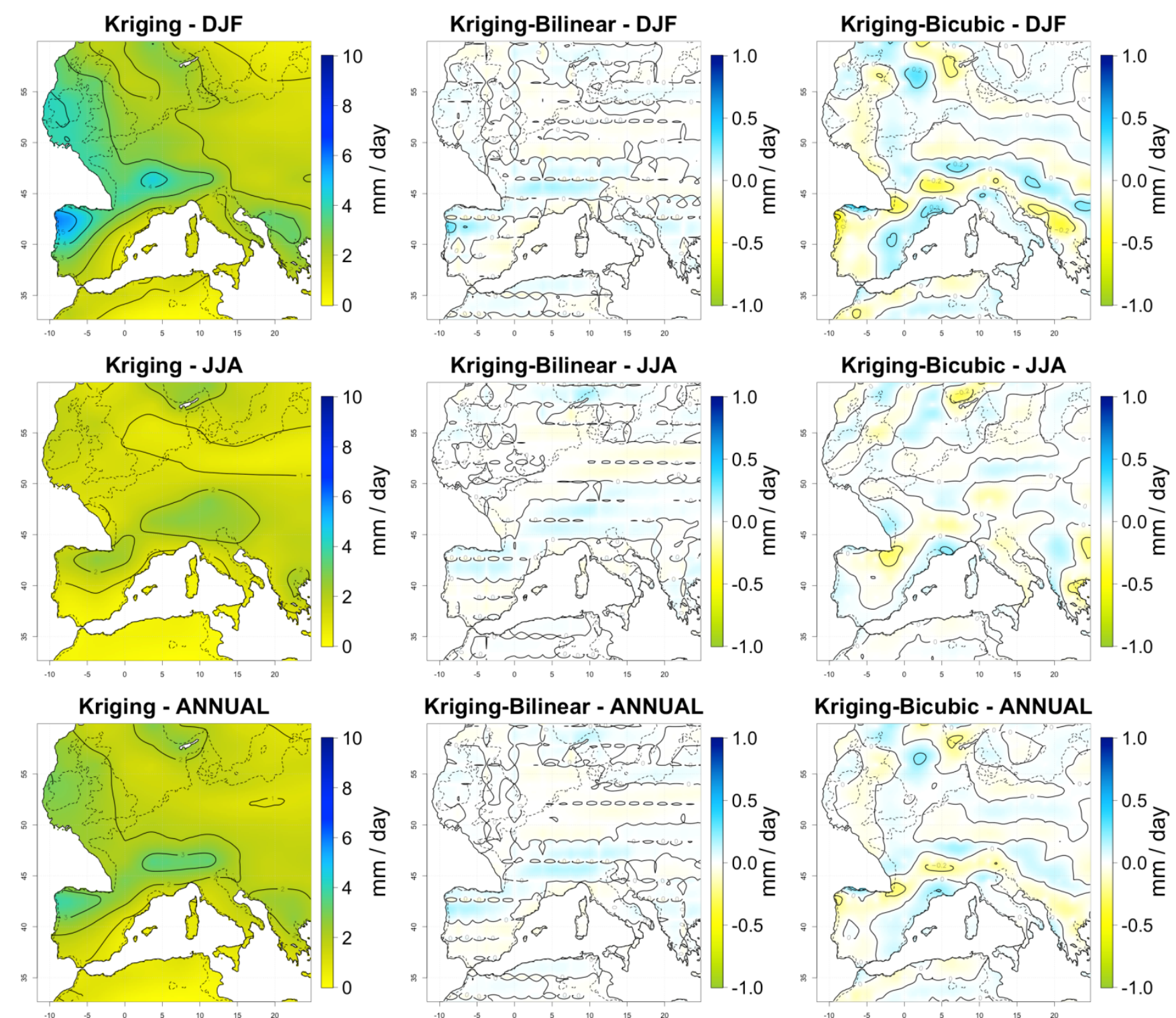

Kriging-Bilinear - ANNUAL

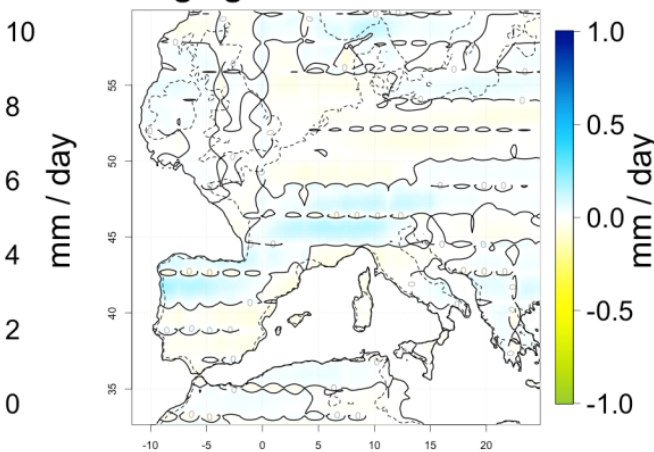

\section{Kriging-Bicubic - ANNUAL}

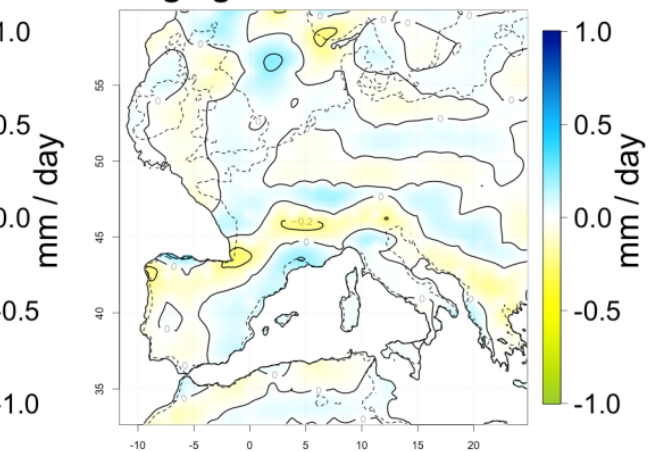

Figure S11. Mean distributions of interpolated daily precipitation over Western Europe during the LGM for winter (December, January, February), summer (June, July, August), and the whole year, computed over 50 years for the kriging interpolation techniques, and difference between the kriging and the other two techniques. Interpolations were performed for each month independently, but results are combined into seasons to summarise the 5 results. 

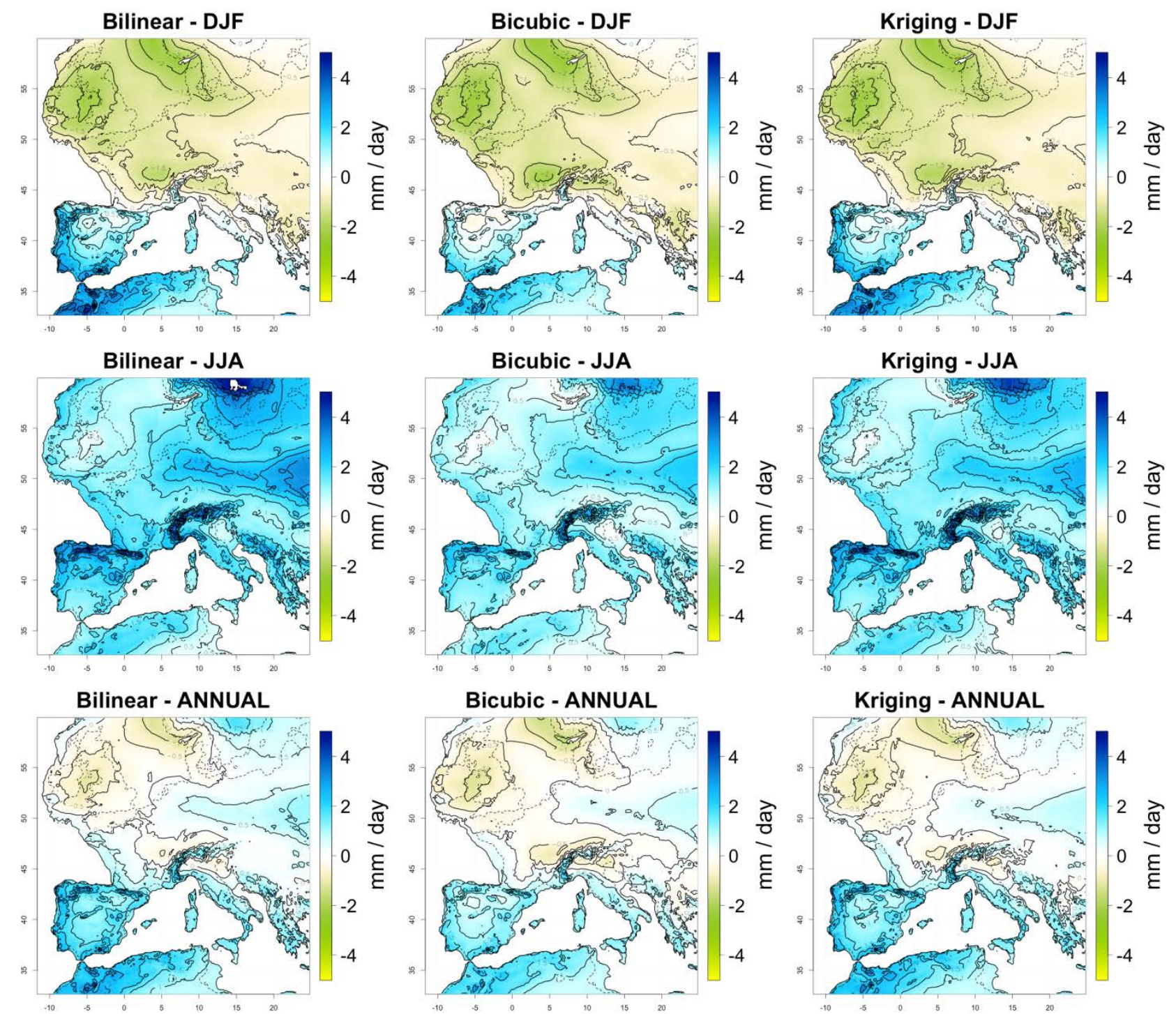

Figure S12. Difference in mean distributions of downscaled and interpolated daily precipitation over Western Europe during the LGM for winter (December, January, February), summer (June, July, August), and the whole year, computed over 50 years, for the three interpolation techniques. 5 Downscaling and interpolations were performed for each month independently, but results are combined into seasons to summarise the results. 

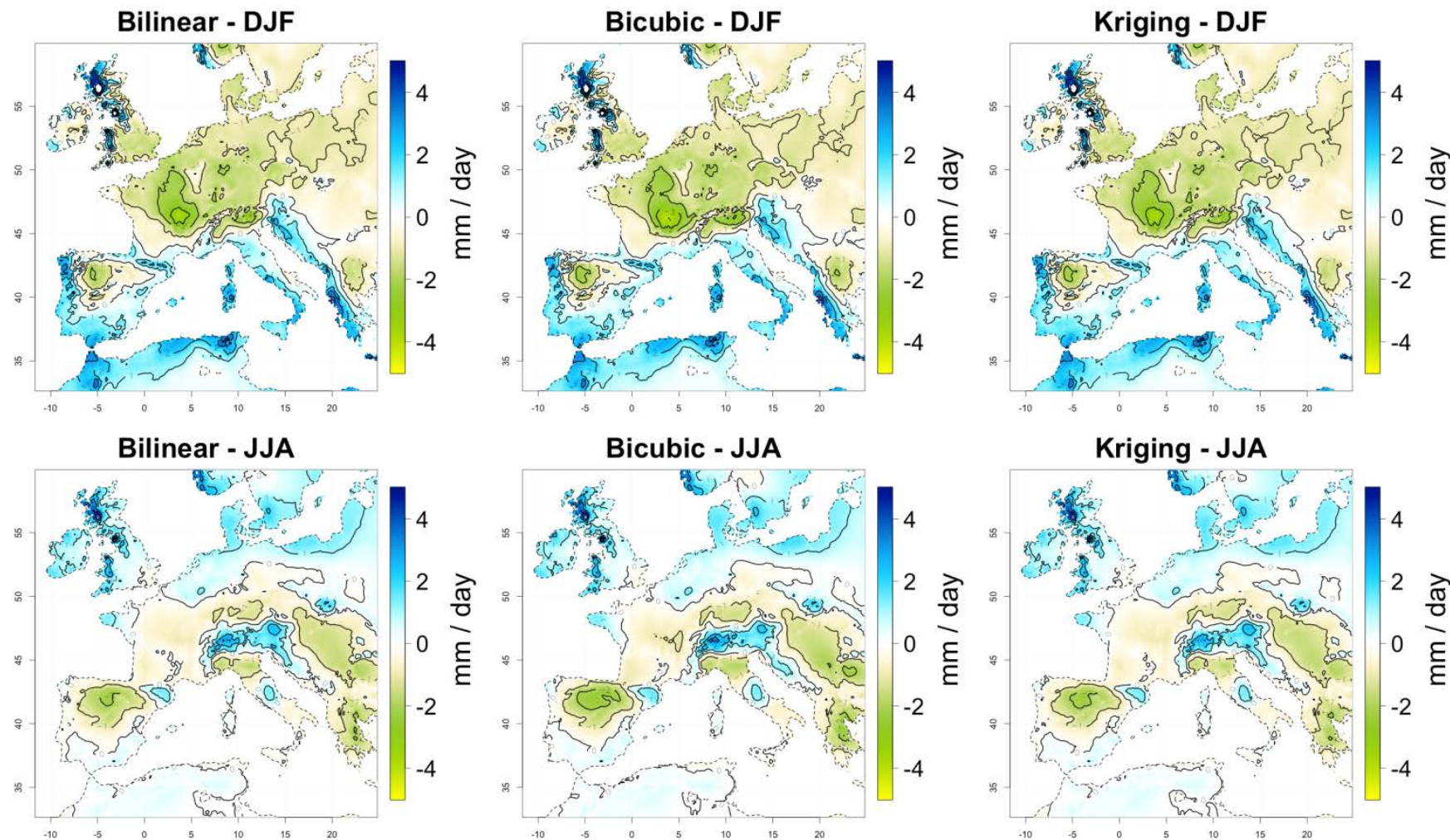

Bilinear - ANNUAL
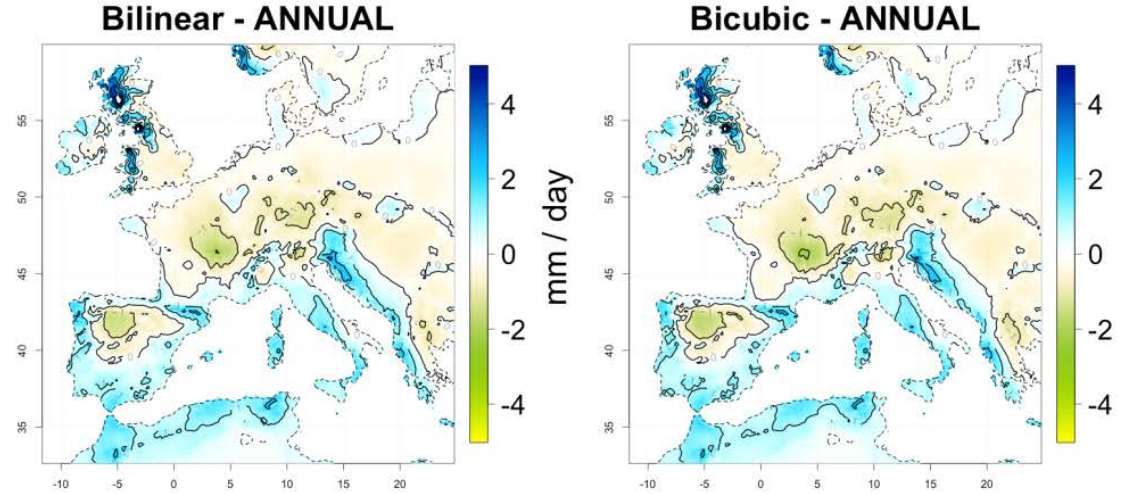

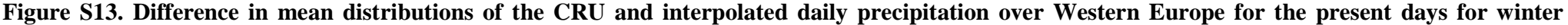

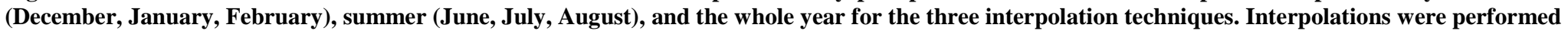
for each month independently, but results are combined into seasons to summarise the results. 

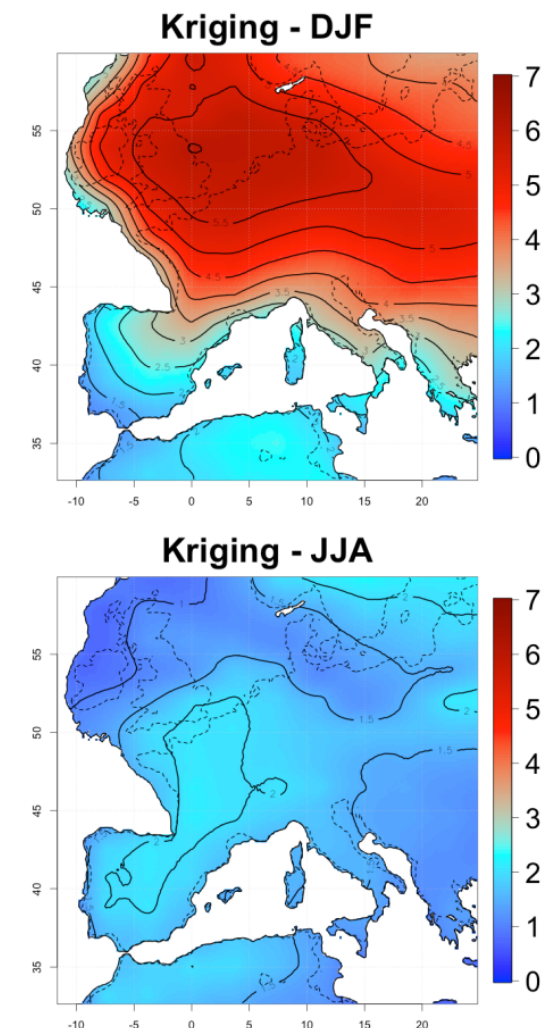

\section{Kriging - ANNUAL}

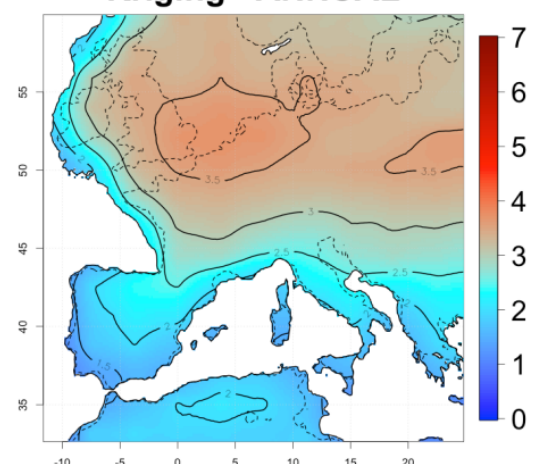

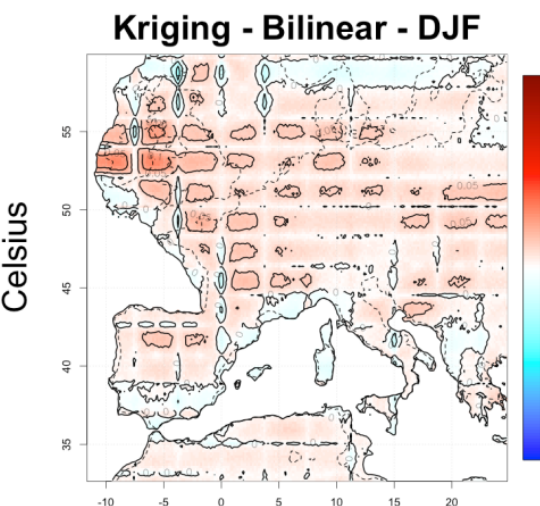

Kriging - Bilinear - JJA

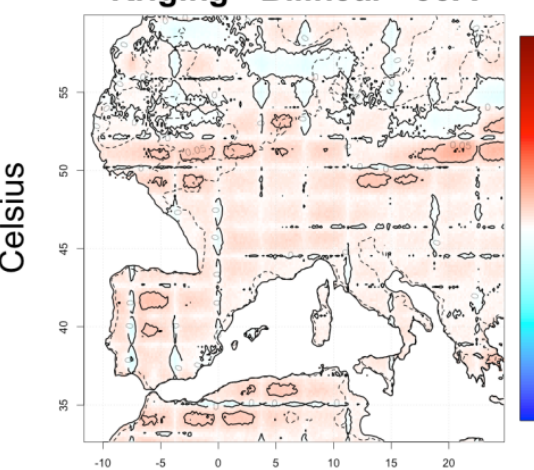

Kriging - Bilinear - ANNUAL

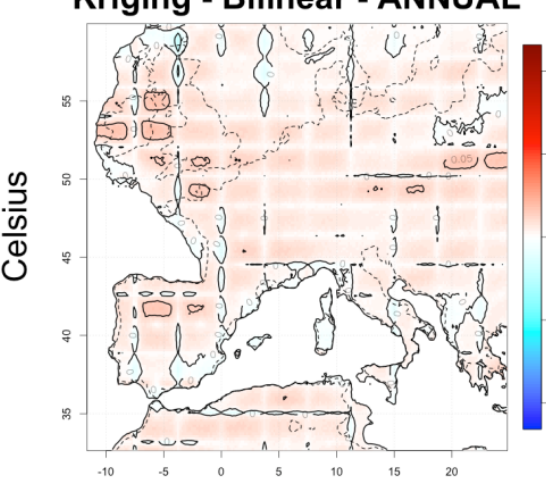

Kriging - Bicubic - DJF

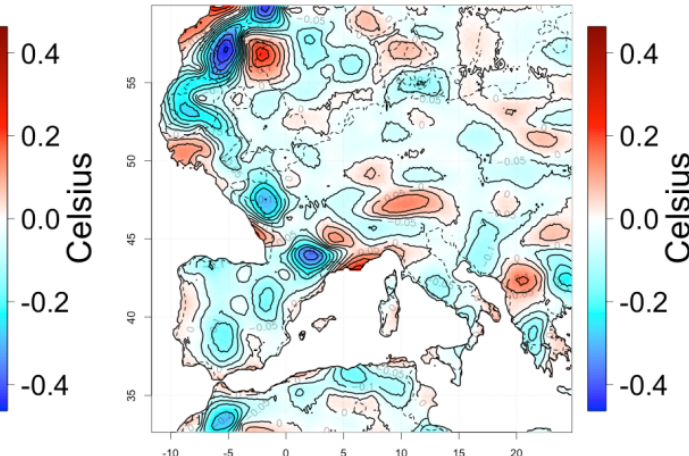

Kriging - Bicubic - JJA

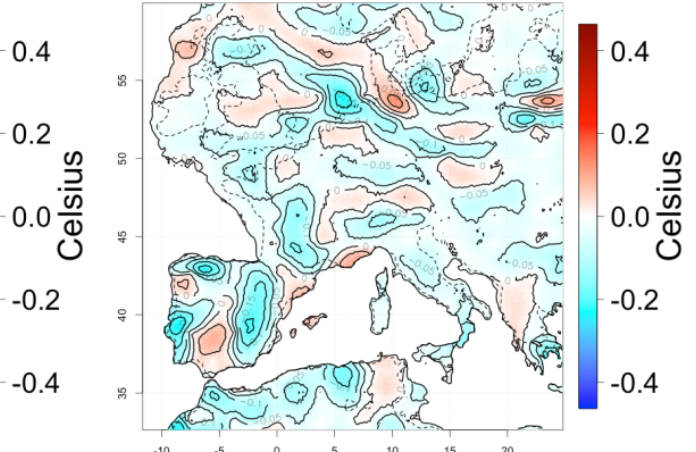

Kriging - Bicubic - ANNUAL

0.4

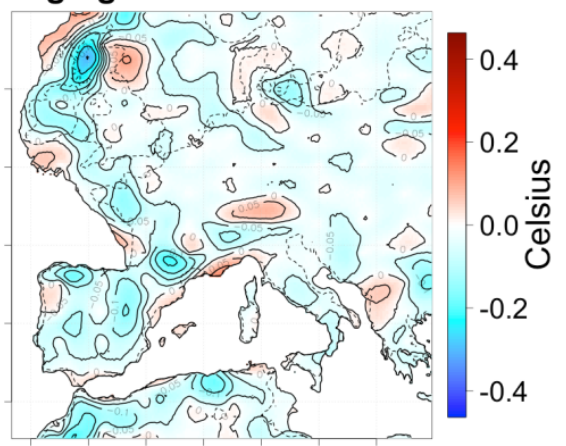

Figure S14. Temporal variations (standard deviation of each month across 50 years) of interpolated monthly mean temperatures over Western Europe during the LGM averaged over winter (December, January, February), summer (June, July, August), and the whole year for the three interpolation techniques. Variability was computed for each month independently, but results are combined into seasons to summarise the results. 

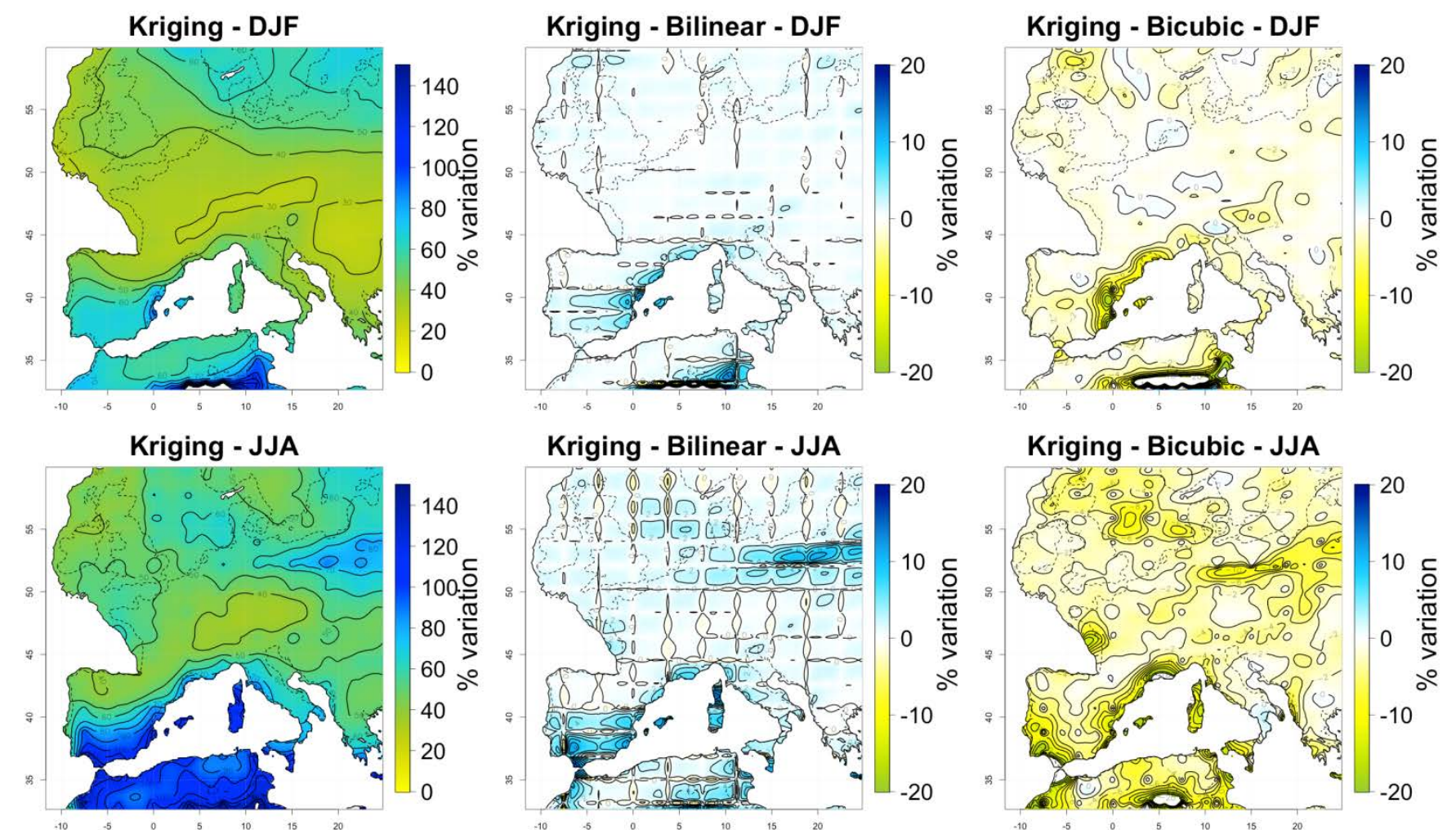

Kriging - Bilinear - JJA

Kriging - Bicubic - JJA
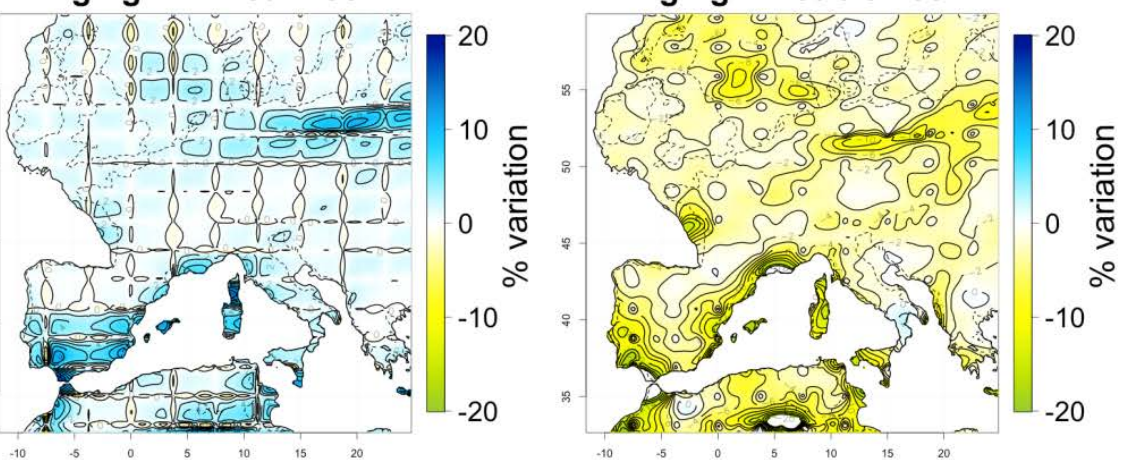

\section{Kriging - ANNUAL}

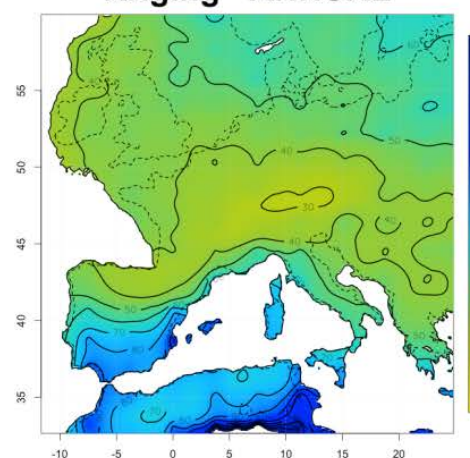

\section{Kriging - Bilinear - ANNUAL}

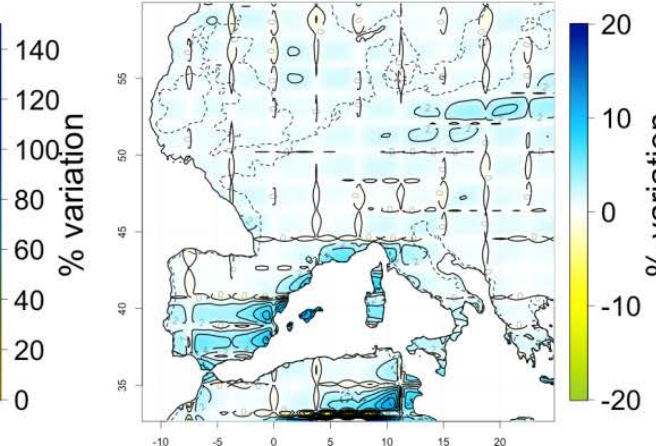

\section{Kriging - Bicubic - ANNUAL}

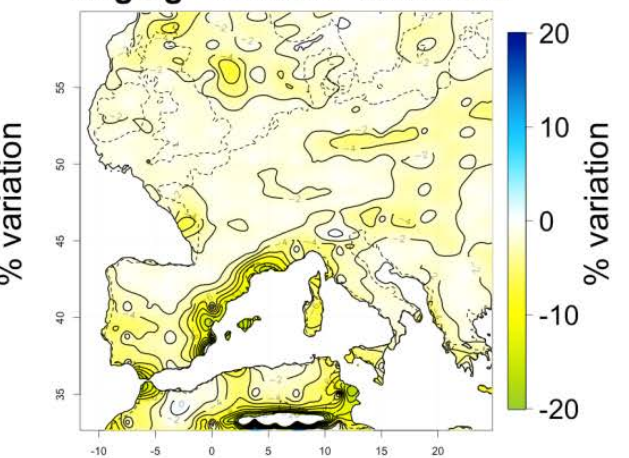

Figure S15. Temporal variations (coefficient of variation of each month across 50 years) of interpolated daily precipitations over Western Europe during the LGM averaged over winter (December, January, February), summer (June, July, August), and the whole year, computed over 50 years for the three interpolation techniques. Variability was computed for each month independently, but results are combined into seasons to summarise the 5 results. 

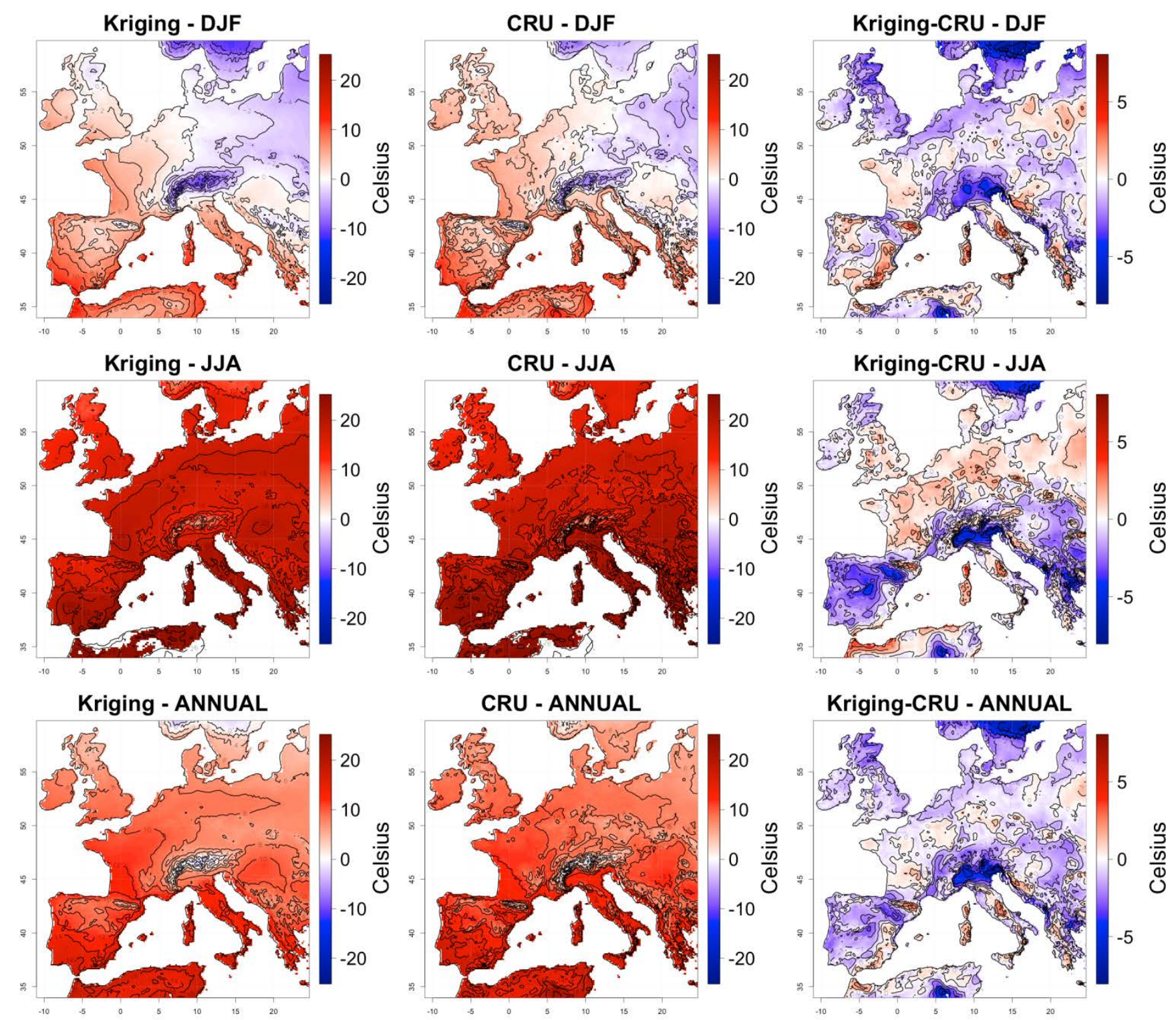

Figure S16. Mean distributions of monthly temperature over Western Europe during the LGM for winter (December, January, February), summer (June, July, August), and the whole year, computed over the 1950-1960 period for the kriging interpolation technique, for the CRU validation dataset, and difference between the two techniques. Downscaling was performed for each month independently, but results are combined into seasons to 5 summarise the results. 

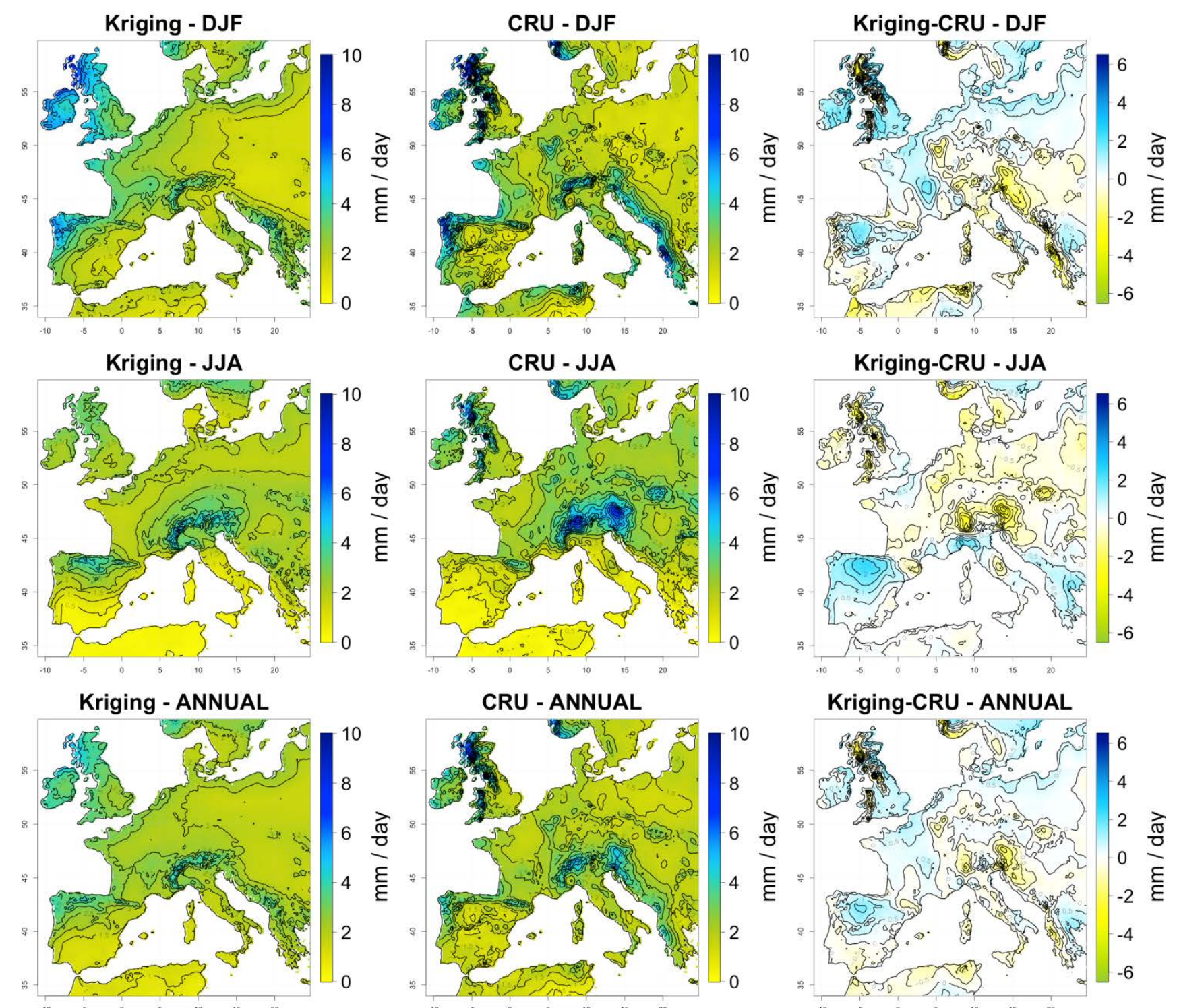

Figure S17. Mean distributions of daily precipitation over Western Europe during the LGM for winter (December, January, February), summer (June, July, August), and the whole year, computed over the 1950-1960 period for the kriging interpolation technique, for the CRU validation dataset, and difference between the two techniques. Downscaling was performed for each month independently, but results are combined into seasons to summarise 5 the results. 

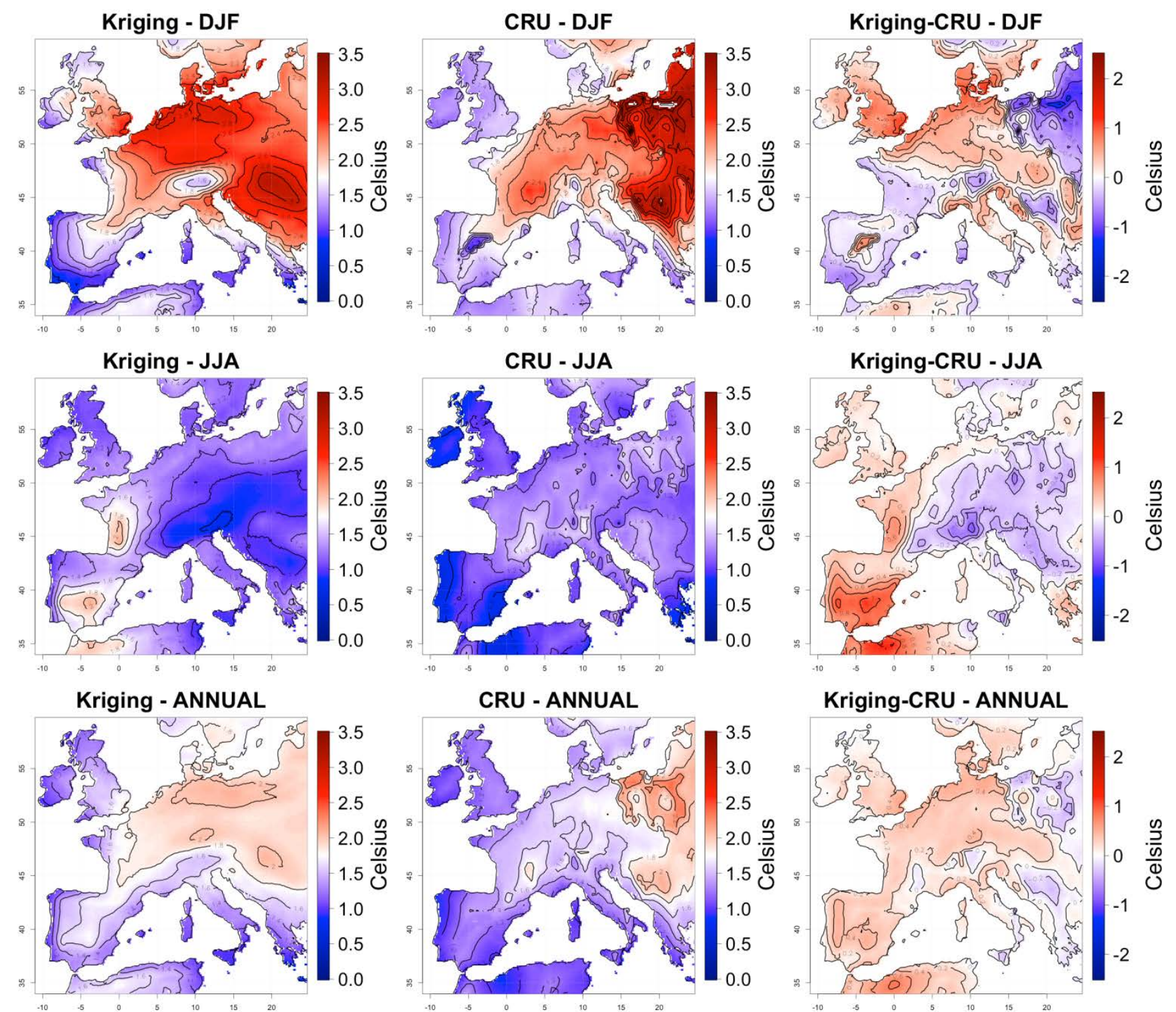

Figure S18. Temporal variations (standard deviation of each month across the 1950-1960 period) of monthly mean temperatures downscaled using the Kriging technique, for the CRU validation dataset and difference the two techniques over Western Europe, over winter (December, January, February), summer (June, July, August) and the whole year. Variability was computed for each month independently, but results are combined into seasons to 5 summarise the results. 

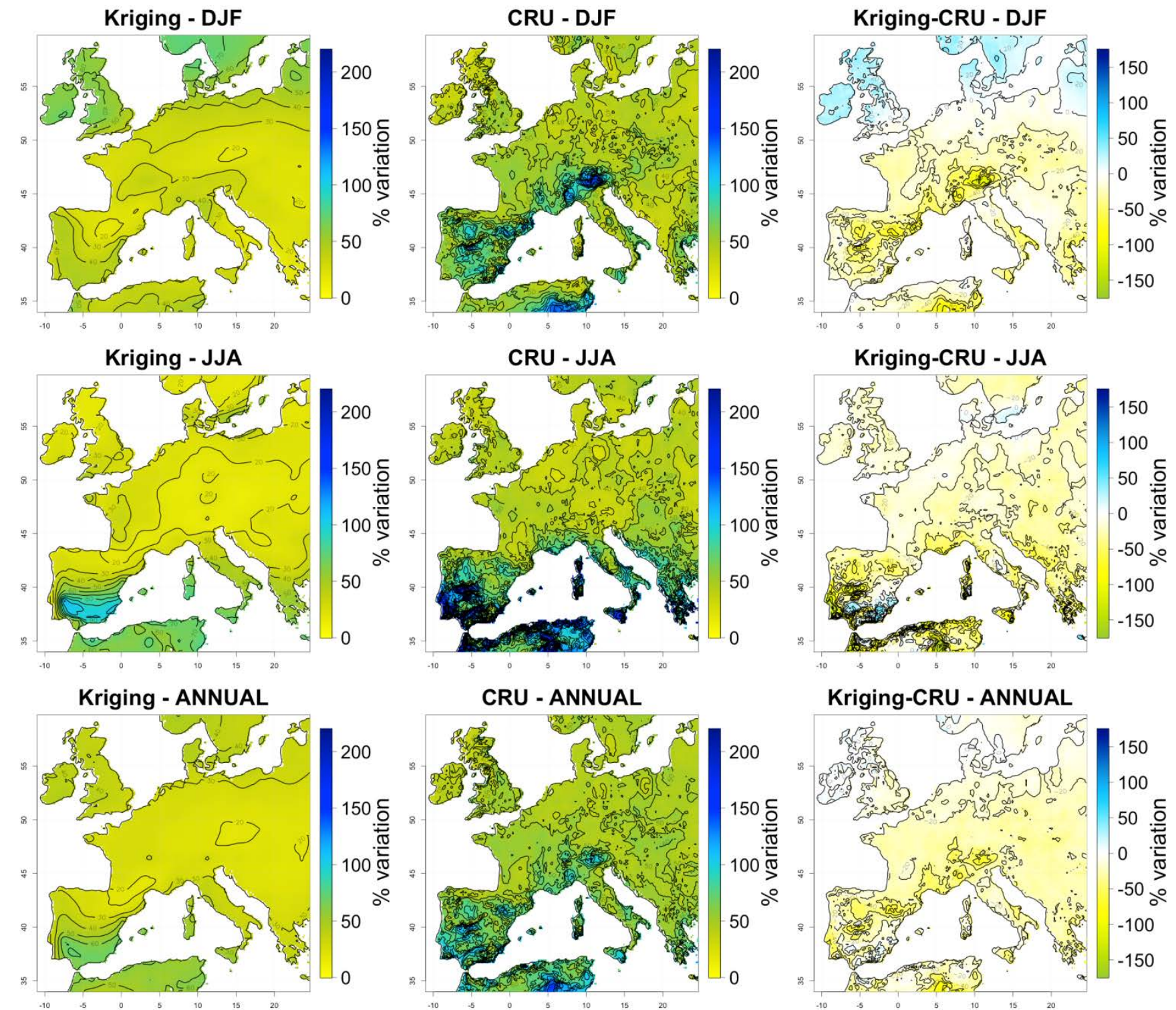

\section{Kriging-CRU - ANNUAL}

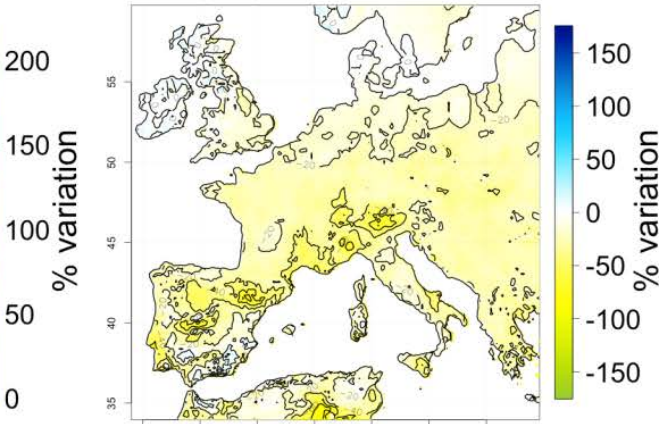

Figure S19. Temporal variations (coefficient of variation of each month across the 1950-1960 period) of daily precipitation downscaled using the Kriging technique, for the CRU validation dataset and difference the two techniques over Western Europe, over winter (December, January, February), summer (June, July, August) and the whole year. Variability was computed for each month independently, but results are combined into seasons to 5 summarise the results. 